\title{
PROCJENA UTJECAJA NA ZDRAVLJE - METODOLOGIJA I NAČELA
}

\author{
Krunoslav Capak i Vedran Poljak
}

Hrvatski zavod za javno zdravstvo Rockefellerova 7, 10000 Zagreb e-mail: krunoslav.capak@hzjz.hr

\begin{abstract}
Sažetak
Procjena utjecaja na zdravlje (engl. Health Impact Assessment - HIA) vrsta je metodologije koja se primjenjuje u razvijenim društvima kao pomoć donositeljima odluka izvan zdravstvenog sektora $u$ procjeni potencijalnih zdravstvenih učinaka predloženih projekata i programa. Pojam HIA označava kombinaciju postupaka, metoda i alata kojima se određena politika, program ili projekt mogu ocijeniti prema svim svojim potencijalnim učincima na zdravlje stanovništva, uključujući i procjenu distribucije tih učinaka unutar populacije. U cilju promicanja što više razine zdravlja populacije, međunarodnim su dogovorom utvrdena četiri osnovna načela HIA-e koje provoditelji procjene trebaju poštovati. Ta su načela: demokratičnost, s naglaskom na pravo gradana da sudjeluju u transparentnom postupku oblikovanja politika koje utječu na njihov život; pravičnost raspodjele utjecaja i moći unutar populacije; promicanje održivog razvoja, uzimajući u obzir sve čimbenike koji utječu na zdravlje ljudi; te, na koncu, etičnost pri korištenju dokaza koji se koriste u izradi HIA-e. Ova načela omogućuju upravljačima i provoditeljima programa primjenu etičkih načela u procesu donošenja odluka. HIA nastoji pronaći rješenja dijalogom izmedu pojedinaca i grupa koji imaju različite, često suprotstavljene interese, vodeći se načelom kojim se štiti interes zdravlja zajednice prije svega.
\end{abstract}

Ključne riječi: procjena utjecaja na zdravlje, procjena utjecaja, zdravlje, etički principi, konsenzus

\section{DEFINICIJA I CILJEVI}

Razvojni infrastrukturni i komercijalni projekti i politike mijenjaju socijalni, ekonomski i fizički okoliš u kojem ljudi žive i rade. Utjecaj svih navedenih transformacija na zdravlje je velik i vrlo složen pa je prije provođenja određenog projekta potrebno procijeniti zdravstvene učinke koje projekt sa sobom nosi (Taylor i Blair, 2002). Zdravstvene učinke izazivaju izravni ili neizravni čimbenici, ali i politike, strategije, programi ili projekti koji mogu izravno, primjerice bukom ili polutantima ispuštenim u zrak, vodu i tlo ili neizravno, posrednim djelovanjem na odrednice zdravlja, primjerice pristupom sadržajima i prostorima za rekreaciju (Barton i Grant, 2006) utjecati na zdravlje stanovništva. Utjecaj se može osjetiti bilo odmah bilo nakon kraćeg, ili dužeg vremenskog razdoblja. Procjena utjecaja na zdravlje (engl. Health Impact Assessment - HIA) je metodologija koja se sve više primjenjuje u državama Europske unije i SAD-a pomažući 
donositeljima odluka izvan zdravstvenog sektora da procijene potencijalne zdravstvene učinke predloženih projekata i programa. HIA se može definirati kao „kombinacija postupaka, metoda i alata kojima se politika, program ili projekt može ocijeniti sa svim svojim potencijalnim učincima na zdravlje stanovništva i distribucijom tih učinaka unutar populacije“ (WHO, 1999). Postaje sve jasnije da se mnogi čimbenici koji određuju zdravlje nalaze izvan tradicionalnog zdravstvenog sektora. Otkrivanje tih odrednica je imperativ u očuvanju zdravlja pojedinca i populacije. Riječ je o sveobuhvatnom procesu koji uključuje procjenu svih odrednica zdravlja: osobnih, društvenih, kulturnih, ekonomskih i ekoloških čimbenika koji bilo pojedinačno bilo u različitim kombinacijama mogu utjecati na zdravstveno stanje pojedinca ili populacije (Taylor i Blair, 2002). Primjerice, treba procijeniti i cijeli niz čimbenika kao što su prihodi, zapošljavanje, obrazovanje, socijalna podrška, za koje je nedvojbeno da mogu utjecati na zdravstveno stanje pojedinca ili populacije. Zdravstveno stanje osobe ili populacije uobičajeno se procjenjuje temeljem pobola, tjelesnog oštećenja, antropoloških mjerenja, smrtnosti i pokazatelja funkcionalnog statusa i kvalitete života. Za razliku od tradicionalnih metoda, HIA obuhvaća i pozitivne i negativne učinke na zdravlje. Osim toga, ova metoda pokušava identificirati zdravstvene dobrobiti koje se mogu ostvariti primjenom određenog projekta. Uključivanje HIA-e u postupke procjene utjecaja na okoliš dalo bi novu kvalitetu postupku okolišne procjene jer bi se zdravlju pristupalo kao jednom od najvažnijih, univerzalnih ljudskih potreba i prava, što je neraskidivo povezano (Birley, 2011). Premda je fizičko i psihičko zdravlje osnovna pretpostavka preživljavanja, to nije dovoljno da se definira zdravlje u cjelini. Definicija zdravlja velikog hrvatskog liječnika dr. Andrije Štampara kao „stanja potpunog fizičkog, psihičkog i socijalnog blagostanja“, kasnije dopunjena s: „a ne samo odsutnosti bolesti“ i danas je službena definicija zdravlja Svjetske zdravstvene organizacije (Sze, 1982). HIA kao revolucionarna i intuitivna metodologija jednostavno nastoji procijeniti moguće ishode javnopolitičkih odluka po zdravlje pojedinaca i populacije. Donositelji značajnih političkih odluka kao i upravljači rizika morali bi se rukovoditi jasnom središnjom pretpostavkom da su zdravlje, vitalnost i dugovječnost univerzalni ciljevi svake nacije. HIA se može koristiti i kao alat za planiranje socijalnih odrednica zdravlja s obzirom na rastući konsenzus o mnogim društvenim, okolišnim i ekonomskim čimbenicima koji utječu na zdravlje. Politike, programi ili projekti se uvijek provode u okviru vrijednosti i ciljeva postavljenih u određenom društvu i u određeno vrijeme. Bitno je da se takvi vrijednosni okviri uzmu u obzir, jer inače postoji opasnost da HIA postane umjetan proces, svrha samom sebi i odvojen od stvarnog političko-ekonomskog okruženja u kojem se provodi.

\section{HIA: VRIJEDNOSTI ILI NAČELA}

Sveobuhvatna HIA obično uključuje najmanje tri različite vrste podataka: kvantitativne podatke o populaciji, rezultate istraživanja o utjecaju sličnih intervencija i savjetovanja s dionicima procesa. Svi se ovi izvori smatraju relevantnima u formiranju prosudbe o mogućim utjecajima i doprinose davanju preporuka za poboljšanje mjera koje bi spriječile 
moguće negativno djelovanje na zdravlje pojedinca ili populacije. Pristup koji primarno procjenjuje utjecaj na zdravlje trebao bi načelno smanjiti negativne učinke na izložene pojedince ili populaciju. Proces HIA omogućuje da se rezultati prethodnih istraživanja uzmu u obzir i primijene u lokalnim okvirima. Gothenburškim su konsenzusom utvrđene četiri osnovne vrijednosti ili načela koja određuju HIA-u „uz promicanje maksimalnog zdravlja stanovništva“. Prva vrijednost ili načelo je demokratičnost, s naglaskom na pravo građana da sudjeluju u transparentnom postupku za oblikovanje, provedbu i evaluaciju politika koje utječu na njihov život, izravno i putem izabranih političkih donositelja odluka. Transparentnost znači da odluke i njihova realizacija budu usklađene s pravilima i propisima koji su ljudima unaprijed poznati. Procesi odlučivanja i provođenja odluka kao i rezultati koji proizlaze iz odluka i postupaka moraju biti pravodobno dostupni javnosti. Drugo načelo HIA-e je pravičnost, čime se ne naglašava samo procjena utjecaja politika na zdravlje stanovništva, nego i raspodjela utjecaja i moći unutar populacije u smislu spola, dobi, etničkog podrijetla i socio-ekonomskog statusa. Jednakost u zdravlju podrazumijeva da bi svatko trebao dobiti istu priliku u ostvarenju potpunog potencijala zdravlja, $s$ minimalnim vanjskim negativnim utjecajima i maksimalnom zdravstvenom zaštitom, i da nitko ne bi trebao biti u nepovoljnom položaju u ostvarivanju tog potencijala. Ovo načelo ima jasne moralne i etičke dimenzije (WHO, 1999). Treće je načelo održivi razvoj, s naglaskom da se i kratkoročni i dugoročni učinci na zdravlje kao i svi veći i manji te direktni i indirektni učinci na zdravlje moraju zajedno uzeti u obzir primjenom metodologije HIA. Koncept održivog razvoja je vrlo složen, započinje procesom društveno - prirodne reprodukcije. Pojedinac je osnovni element utkan u biotičku i abiotičku prirodu procesa materijalnog i socijalnog razvoja koji danas stvaraju ozbiljne probleme prirodi i društvu. Osnovna je misija održivog razvoja mijenjanje tih odnosa u filozofskom, etičkom, estetskom i običajnom pogledu. Da bi se postigao napredak u održivom razvoju, potrebna je prethodna promjena percepcije i načina mišljenja kako pojedinaca tako i dominantnih vrijednosti određenog društva. Humani održivi razvoj je svjestan, slobodan i participativan proces transformacije odnosa među ljudima i ljudi prema okolini i okolišu, s namjerom da se svima pribavi legitiman i efektivan pristup stvaranju i uporabi materijalnih i nematerijalnih, društvenih i ostalih vrijednosti kao pretpostavke ispunjenja potencijala svakog pojedinca. Ovakav razvoj mora jamčiti održavanje života sadašnjih i budućih generacija, kako ljudskih tako i ostalih bića (Trputec i sur., 2014). Posljednje, četvrto načelo je etičko korištenje doka$z a$, kojim se ističe da uporaba kvantitativnih i kvalitativnih dokaza mora biti načelna, temeljena na različitim znanstvenim disciplinama i metodologijama, da bi se dobila što sveobuhvatnija procjena mogućih očekivanih učinaka (WHO, 1999). Etička načela u izradi HIA-e prepoznata su kao načela koja se odnose izravno na rezultate, a ne samo na proces kojim se postižu rezultati, što omogućuje da se u procesu donošenja odluka provoditelji programa rukovode etičkim načelima (Tannahill, 2008). Etičko načelo otvorenosti, koje objašnjava koji se sve učinci mogu pojaviti i tko je nositelj tih učinaka, u središtu je procesa HIA-e (Tannahill i Douglas, 2012). Sudjelovanje dionika u unapređenju zdravlja kroz proces HIA-e poželjan je cilj. Promiče se participativni pristup, 
koji uključuje niz dionika, a mnogi autori opisuju metode za uključivanje ranjivih ili ugroženih skupina (Birley, 2011). Učinci na zdravlje često su i pozitivni i negativni, i odnose se na različite populacijske skupine. Ovakvom se procjenom nastoji jasno i transparentno prikazati učinke i distribuciju učinaka, kao i sve interakcije između utjecaja. HIA-om se također prepoznaje potreba za transparentnošću pri prikazu snage dokaza i razine sigurnosti identificiranih potencijalnih utjecaja na zdravlje (Tannahill i Douglas, 2012). Proces HIA-e koristi biomedicinske podatke i informacije o medicinskim stanjima pojedinaca i navikama koja se mogu smatrati privatnima, ili baze podataka koje pružaju informacije o mogućem stupnju i intenzitetu utjecaja i broju ljudi zahvaćenih utjecajem projekta na zdravlje. Kvantitativni podaci kojima se koristi ovaj proces mogu biti primarni ili sekundarni, $s$ tim da se primarni podaci obično mogu prikupljati samo u opsežnim postupcima HIA-e. Budući da su svi medicinski podaci osjetljivi, njihovo prikupljanje od pojedinaca zahtijeva ispravan etički postupak za koji je potrebno ispuniti širok raspon uvjeta, što u pravilu nije potrebno kada se prikupljaju javno dostupni podaci o odrednicama zdravlja (Patton, 2002). Osim zdravstvenih, kod izrade HIA-e potrebno je procijeniti i socijalne podatke i odrednice.

\section{HIA - ALAT ZA POSTIZANJE KONSENZUSA}

Socijalna epidemiologija, nova znanstvena disciplina, danas sve više dobiva na značenju jer proučava strukturne društvene čimbenike i njihov utjecaj na zdravlje, bolesti i blagostanje stanovništva (Trputec i sur., 2014). Dokazan je utjecaj društvenih čimbenika na zdravlje, kvalitetu i količinu društvenog kapitala, vidljiv ne samo na razini pojedinca, nego i na razini populacijskih podskupina ili čak i cijele populacije (Doyal i Gough, 1991). HIA-om se nastoje pronaći rješenja dijalogom i konsenzusom što je vrlo složeno i teško provedivo. U svakom društvu postoje pojedinci i skupine $s$ različitim, često suprostavljenim, interesima. Dobrim upravljanjem procesom potrebno je posredovati među različitim interesima i izbjegavati sukob vodeći se etičkim načelom koje prije svega štiti interes lokalne zajednice na čijem se području projekt provodi. Da bi se postigli ciljevi održivog razvoja uz razumijevanje povijesnog, kulturnog i društvenog konteksta određene zajednice, konsenzus treba biti usmjeren zahtjevima sveobuhvatne i dugoročne perspektive (Douglas, 2009). Održivi razvoj bi prvenstveno trebao biti usmjeren $\mathrm{k}$ ublažavanju siromaštva, ali on i direktno pozitivno utječe na zdravlje, jer je siromaštvo bitna odrednica zdravlja. Projekti kojima se pravilno upravlja dokazano sadrže mogućnosti za dodatno poboljšanje zdravlja i u tim mogućnostima lokalna zajednica treba ostvariti svoj interes. Dobar primjer mogućnosti za poboljšanje zdravlja lokalne zajednice je osiguravanje rekreacijskih zona, biciklističkih staza i šetnica u okviru infrastrukturnih i drugih projekata jer to otvara mogućnosti ispunjenja smjernica Svjetske zdravstvene organizacije od najmanje 30 minuta tjelesne aktivnosti dnevno ili 150 minuta tjelesne aktivnosti umjerenog intenziteta tjedno (WHO, 2007). Tjelesna neaktivnost je inače jedan od vodećih rizika (četvrti po redu) za razvoj kroničnih nezaraznih bolesti i preuranjene smrti u svijetu i smatra se da je tom riziku izloženo oko 
70\% globalne populacije (Bull i sur. 2014). Podaci za Republiku Hrvatsku (RH) govore da 59,6\% stanovnika pješači dnevno manje od 30 minuta što pozitivno korelira $s$ antropometrijskim podacima da $37,7 \%$ populacije $\mathrm{RH}$ ima prekomjernu tjelesnu masu i $18 \%$ debljinu (Ministarstvo zdravstva RH i HZJZ, 2016). Ovi se loši pokazatelji mogu poboljšati otvaranjem i osmišljavanjem sadržaja kojima bi se povećavala svakodnevna tjelesna aktivnost i smanjio rizik po zdravlje.

Razvoj društva ili gospodarstva može, ali i ne mora, imati za izričiti cilj poboljšanje zdravlja. Kad je cilj projekta poboljšanje zdravlja, procjena zdravstvenog učinka je dio normalnog postupka ocjene projekta i u principu ne treba je provoditi, ali u razvojnim infrastrukturnim ili ekonomskim projektima procjena utjecaja na zdravlje nije dio redovite procedure i zato se metodologija HIA-e koristi primarno u projektima, programima i politikama koji se pokreću izvan zdravstvenog sektora. Premda se može primijeniti čak i retroaktivnim promatranjem, praćenjem i upravljanjem učinaka projekata koji se provode ili su već implementirani, osnovni je cilj primjene HIA-e procjena projekata, programa i politika u fazi planiranja. Postupci i metode potrebne za provedbu HIA-e razlikuju se od standardnih metoda znanstvene prakse. Naime, HIA uključuje opća načela upravljanja, kao što su osiguranje kvalitete i ostvarenje konsenzusa kao i više različitih multidisciplinarnih izvora podataka koji se koriste za izvođenje dokaza i zaključaka, od tradicionalno prihvaćenih znanstvenih podataka vezanih za jednu ili više hipoteza, što joj daje širinu neophodnu za holistički pristup. Definicija i primjena dokaza više nalikuje pravnom postupku koji se provodi pred zainteresiranom javnošću, posebice kad se uzme u obzir da se metodologija primjenjuje na razini politika, programa i projekata koje provodi država, lokalna zajednica, privatni investitori ili, u novije vrijeme, javno-privatna partnerstva. Mada se HIA prvobitno primjenjivala na pojedinim projektima, kod više projekata u jednom području je racionalnije poduzeti stratešku procjenu utjecaja na zdravlje čitavog sektora ili područja (Birley, 2011). Obavezna „Procjena utjecaja na okoliš (PUO) je u većini europskih zemalja dobro zakonodavno regulirana i primjenjuje se $s$ većim ili manjim uspjehom, dok za procjenu socijalnog učinka, a napose procjenu učinka na zdravlje, u većini država EU-a i svijeta nisu ostvarene zakonske pretpostavke. U europskom kontekstu postoji sklonost da se HIA koristi kod primjene vladinih politika zbog njenih etičkih, holističkih i uravnoteženih egalitarnih načela na poveznice između razvoja, okoliša, zdravlja i društva što naglašavaju EPHIA (engl. European Policy Health Impact Assessment) stručnjaci (EPHIA Group, 2004).

Kako bi se uspostavio zakonodavni okvir i pravni kontekst procjene utjecaja razvojnih projekata na zdravlje, potrebno je da HIA postane dio strateških planova pojedinih sektora razvoja društva. Da bi se to postiglo mora se razviti kritična masa znanja o ovoj metodologiji i za njeno provođenje osposobiti dovoljan broj stručnjaka s bazičnim multidisciplinarnim znanjima i vještinama, kako u sektoru upravljača rizika tako i u nacionalnim akademskim zajednicama. Autori se nadaju da će i ovaj pregledni članak pridonijeti podizanju nivoa spoznaje o potrebi provođenja procjene utjecaja na zdravlje prije provođenja i izgradnje razvojnih planova i projekata kako u lokalnoj zajednici tako i na državnoj i međudržavnoj razini. 


\section{LITERATURA}

Barton, H. i Grant, M. (2006). A health map for the local human habitat. The Journal of the Royal Society for the Promotion of Health,126(6):252-253.

Birley, M. H. (2011). Health Impact Assessment Principles and Practice. London: Earthscan.

Bull, F. C., Milton, K. i Kahlmeier, S. (2014). National Policy on Physical Activity: The Development of a Policy Audit Tool (PAT). Journal of Physical Activity \& Health, 11(2): 233-40.

Douglas, M. (2009). How to do Health Impact Assessment: A Guide for Practitioners. Scottish HIA Network, Edinburgh. URL: http://www.healthscotland.com/ uploads/documents/10344Doing\%20a\%20health\%20impact\%20assessment.pdf (studeni, 2016.)

Ministarstvo zdravstva RH i Hrvatski zavod za javno zdravstvo - HZJZ (2016). Europska zdravstvena anketa $u$ hrvatskoj 2014.-2015. European Health Interview Survey (EHIS). Osnovni pokazatelji. Zagreb: Hrvatski zavod za javno zdravstvo. URL: http://www.hzjz.hr/novosti/europska-zdravstvena-anketa-ehis-rezultati-istrazivanja/ (studeni, 2016.)

European Policy Health Impact Assessment (EPHIA) Group (2004). European Policy Health Impact Assessment: A guide. Bruxelles: European Policy Health Impact Assessment Group.

Patton M. Q. (2002). Qualitative research and evaluation methods. 3. izdanje. Thousand Oaks, California: Sage Publications.

Sze, S. (1982). The origins of the World Health Organization: a person memoir 1945-48. Boca Baton: FL, LISZ Publications.

Tannahill, A. (2008) Beyond evidence to ethics: a decisionmaking framework for health promotion, public health, and health improvement. Health Promotion International, 23(4): 380-390.

Taylor, L. i Blair, C. (2002). Introducing Health Impact Assessment (HIA): Informing the decision-making process. London: Health Development Agency.

Trputec, Z., Tibo, A., Kovači, A. i Šantić, N. (2014). Teorija i praksa održivog razvoja, Mostar: Šahinpašić.

Tannahill, A. i Douglas, M. J. (2012). Ethics-based decision-making and health impact assessment. Health Promotion International, 29(1): 98-108.

World Health Organization - WHO (1999). Health impact assessment: Main concepts and suggested approach. The Gothenburg Consensus Paper. Brussel: WHO Regional Office for Europe.

World Health Organization - WHO (2007). A guide for population-based approached to increasing levels of physical activity: What works. Geneva: World Health Organisation. 


\title{
ASSESSING THE IMPACT ON HEALTH - METHODOLOGY AND PRINCIPLES
}

\author{
Krunoslav Capak and Vedran Poljak
}

\begin{abstract}
Health Impact Assessment (HIA) is a type of methodology used in developed societies to help decision-makers outside of the health sector to assess potential health effects of proposed projects and programs. HIA is defined as a combination of procedures, methods and tools used to evaluate a policy, program or project, together with their potential effects on the health of the population, as well as the distribution of such effects within the population. In order to promote the highest possible level of population health, international agreement was reached on four key principles that constitute HIA. These principles are: democracy principle, with emphasis on the rights of citizens to participate in a transparent process of designing policies that affect their own lives; justice principle, in the distribution of influence and power within the population; sustainable development, which takes into account all of the effects on health; and, finally, the ethical use of evidence employed in the development of HIA. Ethical principles in the development of HIA help guide program managers and implementers in decision-making. HIA seeks to use dialogue in order to find solutions to issues between individuals and groups with differing, and often conflicting, interests, using the ethical principles, the main purpose of which is to protect the interests of the community.
\end{abstract}

Keywords: health impact assessment, impact assessment, health, ethical principles, consensus

\section{BEWERTUNG DES GESUNDHEITSEINFLUSSES - METHODOLOGIE UND GRUNDSÄTZE}

\author{
Krunoslav Capak und Vedran Poljak
}

\section{Zusammenfassung}

Die Bewertung des Gesundheitseinflusses (engl. Health Impact Assessment - HIA) ist eine Methodenart, die in entwickelten Gesellschaften angewandt wird, um den Entscheidungsträgern außerhalb des Gesundheitssektors bei der Bewertung von potentiellen Gesundheitseffekten der vorgeschlagenen Projekte und Programme zu helfen. Der Begriff HIA bezeichnet eine Kombination von Verfahren, Methoden und Werkzeugen, mit deren Hilfe eine bestimmte Politik, ein Programm oder ein Projekt hinsichtlich der potentiellen Einwirkung auf die Gesundheit der Bevölkerung bewertet werden kann, einschließlich der Bewertung der Distribution dieser Einwirkungen innerhalb der Population. Damit ein möglichst hohes Niveau der Bevölkerungsgesundheit gefördert werden kann, sind durch einen internationalen Vertrag vier Grundsätze der HIA-e bestimmt worden, die die Bewerter beachten müssen. Diese Grundsätze sind: das Demokratieprinzip, mit der Betonung auf das Recht der Bürger auf ein transparentes Verfahren der Gestaltung von Politiken, die ihre Leben beeinflussen; das Gerechtigkeitsprinzip bei der Einfluss- und Machtverteilung innerhalb der Population; die Förderung der nachhaltigen Entwicklung mit Berücksichtigung aller Faktoren, die die menschliche Gesundheit beeinflussen; und schließlich das Prinzip der Ethik bei der Benutzung von bei der Erstellung von der HIA angewandten Beweisen. Diese Grundsätze ermöglichen den Programmleitern und-durchführern, sich im Prozess der Beschlussfassung an ethische Prinzipien zu halten. Die HIA versucht, durch den Dialog zwischen den Einzelnen und den Gruppen mit oft unterschiedlichen und entgegengesetzten Interessen, Lösungen zu finden und hält sich dabei an das Prinzip, dass vor allem die Gesundheit der Gemeinschaft geschützt werden soll.

Schlüsselwörter: Bewertung des Gesundheitseinflusses, Bewertung des Einflusses, Gesundheit, ethische Prinzipien, Konsens 